Article

\title{
Poly(4-vinylpyridinium) perchlorate as an efficient solid acid catalyst for the chemoselective preparation of 1,1-diacetates from aldehydes under solvent-free conditions
}

\author{
Nader Ghaffari Khaligh* \\ House Research of Professor Reza, Education Guilan, District 1, 41569-17139, Rasht, Iran
}

\section{A R T I C L E I N F O}

Article history:

Received 4 September 2013

Accepted 13 November 2013

Published 20 March 2014

\section{Keywords:}

Poly(4-vinylpyridinium) perchlorate

Chemoselective

Supported catalyst

Acylation

Aldehyde

\begin{abstract}
A B S T R A C T
Poly(4-vinylpyridinium) perchlorate has been used as a supported, recyclable, environmentally-benign catalyst for the formation of acylals from aliphatic and aromatic aldehydes in good to excellent yields under solvent-free conditions. Notably, the reaction conditions were tolerant of ketones. This methodology offers several distinct advantages, including its operational simplicity and high product yield, as well as being green in terms of avoiding the use of toxic catalysts and solvents. Furthermore, the catalyst can be recovered and reused several times without any loss in its activity.
\end{abstract}

(C) 2014, Dalian Institute of Chemical Physics, Chinese Academy of Sciences. Published by Elsevier B.V. All rights reserved.

\section{Introduction}

Considerable research efforts have recently been directed towards the development of "cleaner production" methods aimed at preventing the occurrence of serious environmental pollution problems, and four main approaches have been developed in this regard, with the use of solvent-free conditions and low loadings of the catalyst representing two of the most effective of these methods for the synthesis of compounds in an environmentally friendly manner [1,2]. Green chemistry also requires the recovery and reuse of the catalyst. One way to overcome the problem of reusability associated with the use of a homogeneous catalyst is to chemically anchor the reactive centers onto a solid support with a large surface area [3]. In systems of this type, the reactive centers are highly mobile, in the same way as traditional acid catalysts. At the same time, however, these species have the advantage of being recyclable. Poly(4-vinylpyridine) $(\mathrm{P}(4-\mathrm{VP}))$ has been reported as an at- tractive support for the immobilization of mineral acids because of the basic nature of its pyridyl groups [4].

Research towards the development and application of solid acids as economically and environmentally benign catalysts has attracted considerable attention from both academia and industry, because as well as being inexpensive and environmentally friendly, these reagents are non-corrosive and their disposal does not lead to any significant effluent problems [5-16].

The protection of aldehydes serves as an important transformation for the preparation of feedstocks for the synthesis of poly functional compounds and natural products. The acetylation of aldehydes represents one of the most useful strategies for the protection of aldehydes because of the ease with which these compounds can be prepared and subsequently converted back to the parent aldehydes [17-21]. Furthermore, these compounds are stable to neutral and basic conditions [19]. The synthesis of acylal is usually achieved via the reaction of an aldehyde with acetic anhydride $\left(\mathrm{AC}_{2} \mathrm{O}\right)$ in the presence of a

* Corresponding author. Tel: +982166431738; Fax: +982166934046; E-mail: ngkhaligh@gmail.com, ngkhaligh@guilan.ac.ir 
protic acid [15,22-30], Lewis acid [19,30-44], or heterogeneous catalyst [45-54]. This transformation can also be conducted under neutral conditions [55].

Many application of these methods, however, has been limited either by (1) the requirement for costly and water sensitive catalysts (e.g., triflates); (2) the special effort required for the preparation of the catalyst (e.g., Bi(OTf) 3 , Nafion-H, and yttria-zirconia); (3) the requirement for an excess of acetic anhydride; (4) the requirement for low temperature conditions; or (5) the potential for the occurrence of side reactions with acid sensitive substrates (e.g., triflates). The high cost and moisture sensitivity of these catalysts has become a major concern for the industrial application of these processes. Although these methods are generally efficient, they can sometimes be difficult to implement, in that there can be issues associated with the preparation of an acylal from furfural [51] and longer reaction time may be required for the preparation of aliphatic and $\alpha, \beta$-unsaturated aldehydes [48]. Furthermore, some of these catalysts have been reported to give the protection products as well as the deprotection products. With this in mind, there is an urgent need for the development of a new methodology using an inexpensive and mild catalyst that is capable of overcoming the limitations described above for the preparation of acylals from the corresponding aldehydes.

We recently demonstrated the applicability of poly(4-vinylpyridinium) perchlorate $\left(\mathrm{P}(4-\mathrm{VPH}) \mathrm{ClO}_{4}\right)$ for the acetylation of alcohols, phenols, amines and thiols [56], as well as its application to the one-pot synthesis of substituted coumarins under ultrasonic irradiation [57]. Herein, we report the development of a new mild and efficient method for the chemoselective preparation of 1,1-diacetates from aldehydes at room temperature under solvent-free conditions (Scheme 1).

\section{Experimental}

\subsection{General}

All chemicals were purchased from Merck, Aldrich and Fluka and were used without further purification. The reaction products were characterized based on their physical properties and by comparison with authentic samples. The reactions were monitored by thin-layer chromatography (TLC) using silica gel SIL G/UV 254 plates.

The MS spectra were measured under gas chromatograph (GC, $70 \mathrm{eV}$ ) conditions. The infrared (IR) spectra were recorded on a Perkin Elmer 781 Spectrophotometer. The Ultraviolet (UV) spectra were recorded on an Agilent 8453 UV-vis spectrophotometer at room temperature. The ${ }^{1} \mathrm{H}$ NMR spectra were recorded on a Bruker Avance $300 \mathrm{MHz}$ instrument, whereas the ${ }^{13} \mathrm{C}$ NMR data were collected on a Bruker Avance $75 \mathrm{MHz}$

$$
\begin{gathered}
\mathrm{R}-\mathrm{CHO} \frac{\mathrm{P}(4-\mathrm{VPH}) \mathrm{ClO}_{4}}{\mathrm{Ac}_{2} \mathrm{O}, \text { solvent-free, r.t. }} \mathrm{R}-\mathrm{CH}(\mathrm{OAc})_{2} \\
\mathrm{R}=\text { Alkyl or aryl }
\end{gathered}
$$

Scheme 1. Chemoselective preparation of 1,1-diacetates from aldehydes. instrument. All chemical shifts are quoted in parts per million (ppm) relative to tetramethylsilane (TMS) in a deuterated solvent. The melting points were recorded on a Büchi B-545 apparatus in open capillary tubes.

\subsection{General procedure for the acetylation of aldehydes}

$\mathrm{P}(4-\mathrm{VPH}) \mathrm{ClO}_{4}$ was prepared according to literatures $[56,57]$. Briefly, the aldehyde (5 mmol), $\mathrm{Ac}_{2} \mathrm{O}(5-7.5 \mathrm{mmol})$ and $\mathrm{P}(4-\mathrm{VPH}) \mathrm{ClO}_{4}(20 \mathrm{mg}, 0.016 \mathrm{mmol})$ were added to a $25-\mathrm{mL}$ batch reactor equipped with a distillation condenser, and the resulting mixture was stirred at room temperature for a specified time (Table 1). The amount of $\mathrm{AC}_{2} \mathrm{O}$ used in the reaction was varied in the range of 1.0-1.5 equivalents to assist in the dissolution of the aldehyde and the stirring of the reaction mixture. Upon completion of the reaction (as determine by TLC), the mixture was diluted with diethyl ether $\left(\mathrm{Et}_{2} \mathrm{O}, 2 \times 10\right.$ $\mathrm{mL}$ ) and filtered to allow for the recovery of the catalyst. The ether layer was collected and washed sequentially with a saturated solution of $\mathrm{NaHCO}_{3}(5 \mathrm{~mL})$ and water $(3 \times 5 \mathrm{~mL})$ before being dried over anhydrous $\mathrm{Na}_{2} \mathrm{SO}_{4}$. The solvent was then removed in vacuo to give the pure acylal product as a residue, which was recrystallized from $n$-hexane or cyclohexane. The recovered catalyst was dried in an oven under vacuum at $50{ }^{\circ} \mathrm{C}$ and reused.

\subsection{General procedure for the deprotection of 1,1-diacetates}

A mixture of the 1,1-diacetate of the aldehyde ( $5 \mathrm{mmol})$ and $\mathrm{P}(4-\mathrm{VPH}) \mathrm{ClO}_{4}(20 \mathrm{mg})$ in ethanol $(5 \mathrm{~mL})$ was stirred at 50-60 ${ }^{\circ} \mathrm{C}$. Upon completion of the reaction (as determined by TLC), the mixture was filtered to remove the catalyst. The filtrate was collected and distilled to dryness to give a residue, which was partitioned between water $(10 \mathrm{~mL})$ and $\mathrm{Et}_{2} \mathrm{O}(5 \mathrm{~mL})$. The ether layer was collected and the aqueous layer was back-extracted with $\mathrm{Et}_{2} \mathrm{O}(2 \times 5 \mathrm{~mL})$. The combined ether layers were washed with a saturated solution of $\mathrm{NaHCO}_{3}(5 \mathrm{~mL})$ and dried over anhydrous $\mathrm{Na}_{2} \mathrm{SO}_{4}$. The solvent was removed under vacuum to give the crude product as a residue, which was purified by silica gel column chromatography ( $n$-hexane: ethyl acetate $=85: 15$ $(\mathrm{v} / \mathrm{v})$ ) to afford the pure aldehyde.

The spectral data of some representative products as follows.

1,1-Diacetate of 2-methylbenzaldehyde (Table 2, entry 7). White solid; m.p. $65-67{ }^{\circ} \mathrm{C}$; IR (KBr): $v=3650,3500,3010$, 2910, 1760, 1610, 1590, 1490, 1430, 1370, 1245, 1200, 1160, 1060, 1010, 970, 940, 917, 790, 760, 700, 670, $600 \mathrm{~cm}^{-1} ;{ }^{1} \mathrm{H}$ NMR (DMSO- $\left.d_{6}, 300 \mathrm{MHz}\right) \delta=2.13\left(\mathrm{~s}, 6 \mathrm{H}, 2 \times \mathrm{COCH}_{3}\right), 2.38(\mathrm{~s}$, $\left.3 \mathrm{H}, \mathrm{CH}_{3}\right), 7.02$ (d, $\left.J=7.9 \mathrm{~Hz}, 1 \mathrm{H}, \mathrm{ArH}\right), 7.50(\mathrm{~d}, J=7.9 \mathrm{~Hz}, 1 \mathrm{H}$, ArH), 7.60-7.66 (m, 2H, ArH), 8.04 (s, 1H, CH(OAc)2); ${ }^{13} \mathrm{C}$ NMR (DMSO- $\left.d_{6}, 75 \mathrm{MHz}\right) \delta=167.5,147.7,135.4,133.8,127.9,125.1$, 123.5, 87.8, 21.9, 21.0.

1,1-Diacetate of 3,4-dimethoxybenzaldehyde (Table 2, entry 11). White solid; m.p. $72-74{ }^{\circ} \mathrm{C}$; IR (neat): $v=3035,2985,1760$, 1610, 1595, 1530, 1465, 1370, 1310, 1245, 1210, 1170, 1100, 995, 970, 840, $760 \mathrm{~cm}^{-1}$; ${ }^{1} \mathrm{H} \mathrm{NMR}\left(\mathrm{CDCl}_{3}, 300 \mathrm{MHz}\right) \delta=2.10(\mathrm{~s}$, $\left.6 \mathrm{H}, 2 \times \mathrm{COCH}_{3}\right), 3.06\left(\mathrm{~s}, 3 \mathrm{H}, \mathrm{OCH}_{3}\right), 3.89\left(\mathrm{~s}, 3 \mathrm{H}, \mathrm{OCH}_{3}\right), 6.81(\mathrm{~d}, J$ 
$=4.9 \mathrm{~Hz}, 1 \mathrm{H}, \mathrm{ArH}), 6.88(\mathrm{dd}, J=4.9, J=1.1 \mathrm{~Hz}, 1 \mathrm{H}, \mathrm{ArH}), 6.98(\mathrm{~d}$, $J=1.1 \mathrm{~Hz}, 1 \mathrm{H}, \mathrm{ArH}), 7.97$ (s, $\left.1 \mathrm{H}, \mathrm{CH}(\mathrm{OAc})_{2}\right) ;{ }^{13} \mathrm{C} \mathrm{NMR}\left(\mathrm{CDCl}_{3}, 75\right.$ MHz) $\delta=167.5,149.8,148.3,147.7,123.5,113.4,113.3,87.8$, 55.6, 54.5, 23.3.

1,1-Diacetate of isophthaldehyde (Table 2, entry 19). White solid; m.p. 96-98 ${ }^{\circ} \mathrm{C}$; IR (KBr): $v=3002,2920,1752,1430$, $1362,1340,1240,1200,1158,1106,1060,1000,942,910$, $808,710,680,650,600,530,510 \mathrm{~cm}^{-1} ;{ }^{1} \mathrm{H}$ NMR (DMSO- $d_{6}, 300$ $\mathrm{MHz}) \delta=2.10\left(\mathrm{~s}, 12 \mathrm{H}, 4 \times \mathrm{COCH}_{3}\right), 7.52(\mathrm{~d}, J=7.8 \mathrm{~Hz}, 1 \mathrm{H}, \mathrm{ArH})$, $8.00(\mathrm{~d}, J=7.9 \mathrm{~Hz}, 1 \mathrm{H}, \mathrm{ArH}), 8.17\left(\mathrm{~s}, 2 \mathrm{H}, 2 \times \mathrm{CH}(\mathrm{OAc})_{2}\right), 8.43(\mathrm{~m}$, $2 \mathrm{H}, \mathrm{ArH}$ ); ${ }^{13} \mathrm{C}$ NMR (DMSO- $\left.d_{6}, 75 \mathrm{MHz}\right) \delta=167.0,141.1,129.6$, 128.8, 126.3, 102.3, 22.5.

1,1-Diacetate of terephthaldehyde (Table 2, entry 20). White solid; m.p. $164-166{ }^{\circ} \mathrm{C}$; IR (KBr): $v=3020,2910,1758,1430$, $1378,1338,1200,1118,1060,1008,960,940,910,852,818$, $604,580,540 \mathrm{~cm}^{-1} ;{ }^{1} \mathrm{H} \mathrm{NMR}\left(\mathrm{CDCl}_{3}, 300 \mathrm{MHz}\right) \delta=2.37(\mathrm{~s}, 12 \mathrm{H}$, $\left.4 \times \mathrm{COCH}_{3}\right), 7.41(\mathrm{~s}, 4 \mathrm{H}, \mathrm{ArH}), 8.26\left(\mathrm{~s}, 2 \mathrm{H}, 2 \times \mathrm{CH}(\mathrm{OAc})_{2}\right) ;{ }^{13} \mathrm{C}$ $\mathrm{NMR}\left(\mathrm{CDCl}_{3}, 75 \mathrm{MHz}\right) \delta=167.0,141.1,129.8,104.3,21.5$.

\section{Results and discussion}

The reaction between 4-chlorobenzaldehyde ( $5 \mathrm{mmol})$ and acetic anhydride ( $5 \mathrm{mmol}$ ) was selected as a model reaction to optimize the reaction conditions. The model reaction was conducted at room temperature in a variety of different solvents ( 5 $\mathrm{mL})$, as well as being conducted under solvent-free conditions, using $\mathrm{P}(4-\mathrm{VPH}) \mathrm{ClO}_{4}(20 \mathrm{mg})$ as the catalyst. The results of these solvent screening experiments are shown in Table 1 . The yield for the reaction varied depending upon the solvent used and decreased in the order solvent-free $>\mathrm{AcOH}>$ diethyl ether $>$ acetonitrile $(\mathrm{MeCN})>$ ethanol $>$ dichloromethane (DCM) and tetrahydrofuran (THF). The highest yield for the reaction with the shortest reaction time was achieved under solvent-free conditions (Table 1, entries 7-11). The polar aprotic solvent acetonitrile (Table 1, entry 4) and the polar protic solvent ethanol (Table 1, entry 6) gave similar conversion. Surprisingly, however, when ethanol was used as the solvent, diethyl ether and ethyl acetate also were observed as major products from the reaction after $1 \mathrm{~h}$. The use of the polar aprotic solvents DCM and THF led to significant reductions in the conversion (Table 1, entries 2 and 3 ). This could be attributed to (I) a reduction in

Table 1

Effects of different amounts of catalyst, acylating agent, and solvent on the 1,1-diacetylation of 4-chlorobenzaldehyde.

\begin{tabular}{lccccc}
\hline Entry & $\begin{array}{c}\text { Catalyst } \\
\text { amount }(\mathrm{mg})\end{array}$ & $\begin{array}{c}\mathrm{Ac}_{2} \mathrm{O} \\
\text { (equiv.) }\end{array}$ & $\begin{array}{c}\text { Solvent } \\
(5 \mathrm{~mL})\end{array}$ & $\begin{array}{c}\text { Time } \\
(\mathrm{min})\end{array}$ & $\begin{array}{c}\text { Yield }^{\mathrm{a}} \\
(\%)\end{array}$ \\
\hline 1 & 20 & 1 & $\mathrm{AcOH}$ & 60 & 89 \\
2 & 20 & 1 & $\mathrm{DCM}$ & 60 & trace \\
3 & 20 & 1 & $\mathrm{THF}$ & 60 & trace \\
4 & 20 & 1 & $\mathrm{MeCN}$ & 60 & 18 \\
5 & 20 & 1 & $\mathrm{Et}_{2} \mathrm{O}$ & 60 & 32 \\
6 & 20 & 1 & $\mathrm{EtOH}$ & 60 & 12 \\
7 & 20 & 1 & - & 1 & 92 \\
8 & 20 & 1.5 & - & 1 & 97 \\
9 & 10 & 1 & - & 1 & 82 \\
10 & 10 & 1.5 & - & 1 & 85 \\
11 & 30 & 1 & - & 1 & 92 \\
12 & - & 1 & - & 120 & - \\
\hline
\end{tabular}

a Determined by GC-MS. the diffusion of the substrate and acylating agent molecules in the presence of the solvent, and (II) interference from the solvent molecules, which could be adsorbed onto the active sites of the $\mathrm{P}(4-\mathrm{VPH}) \mathrm{ClO}_{4}$ to effectively block the activity of the catalyst [58-60].

On increasing the catalyst amount from 10 to $20 \mathrm{mg}$, the product yield also increased (Table 1, entries 7-10). Further increases in the catalyst amount (20-30 mg) did not have a discernible impact on the yield or the reaction time (Table 1, entries 10 and 11). An increase in amount of the acetic anhydride led to a small increase in the product yield (Table 1, entries 7,8 and 9,10). Interestingly, when the reaction was conducted in the absence of the catalyst at room temperature, no product was formed, even after a reaction time in excess of $2 \mathrm{~h}$. The use of 1.5 equivalents of $\mathrm{Ac}_{2} \mathrm{O}$ was preferred to 1.0 equivalent, because the reaction did not always proceed to completion with 1.0 equivalents due to the solidification of the 1,1-diacetate.

Blank experiments for the 1,1-diacetylation of furfural were carried out in the presence of the starting materials (i.e. $\mathrm{P}(4-\mathrm{VP})$ and $\mathrm{HClO}_{4}$ ) used for the preparation of the $\mathrm{P}(4-\mathrm{VPH}) \mathrm{ClO}_{4}$ reagent under similar reaction conditions. Furfural was selected as a model substrate for the optimization experiments because the diacetylation of furfural is usually difficult to achieve under conventional conditions because of the occurrence of competitive side reactions (i.e., decomposition or polymerization). When the reaction was conducted in the presence of $\mathrm{P}(4-\mathrm{VP})$, the product was formed in a yield of $69 \%$ after $30 \mathrm{~min}$, whereas the use of aqueous $\mathrm{HClO}_{4}$ led to a mixture of products after the same time period. These results were in sharp contrast to the result achieved using $\mathrm{P}(4-\mathrm{VPH}) \mathrm{ClO}_{4}$. The poor performance of $\mathrm{HClO}_{4}$ was attributed to its strong acidity, which would enhance the occurrence of side reactions. Based on these results, it is clear that the current protocol is much more effective for the 1,1-diacylation of furfural in terms of reaction time and yield (Table 2 ).

Based on the results above, it was decided that the optimum conditions for the acetylation reaction would be the use of solvent-free conditions at room temperature with $20 \mathrm{mg}$ of the catalyst. With the optimized conditions in hand, we proceeded to evaluate the scope of the transformation with a variety of different aldehydes, and the results are summarized in Table 3. It clearly indicated that the optimized conditions could be successfully applied to a variety of different aldehydes. Benzaldehyde derivatives (Table 3, entries 1-13), as well as furfural (Table 3, entry 14), aliphatic (Table 3, entries 15 and 16), and allylic (Table 3, entry 17) aldehydes were all successfully acet-

\section{Table 2}

Controlled blank experiments for the 1,1-diacetylation of furfural in the presence of $\mathrm{P}(4-\mathrm{VP})$ cross-linked with $2 \%$ divinylbenzene 60 mesh; Fluka Chemica, $\mathrm{HClO}_{4}$ ( as a $70 \%$ aqueous solution) and $\mathrm{P}(4-\mathrm{VPH}) \mathrm{ClO}_{4}$.

\begin{tabular}{lcccc}
\hline Entry & Catalyst & $\begin{array}{c}\text { Catalyst } \\
\text { amount }\end{array}$ & $\begin{array}{c}\text { Time } \\
(\mathrm{min})\end{array}$ & Yield $^{\mathrm{a}}(\%)$ \\
\hline 1 & $\mathrm{P}(4-\mathrm{VP})$ & $20 \mathrm{mg}$ & 30 & 69 \\
2 & $\mathrm{HClO}_{4}$ & $0.05 \mathrm{~mL}$ & 30 & Mixture of products \\
3 & $\mathrm{P}(4-\mathrm{VPH}) \mathrm{ClO}_{4}$ & $20 \mathrm{mg}$ & 1 & 90 \\
\hline
\end{tabular}

Reaction conditions: furfural $1.0 \mathrm{mmol}, \mathrm{Ac}_{2} \mathrm{O} 1.5 \mathrm{mmol}$, room temperature, solvent free. 
Table 3

Acylation of aldehydes in the presence of $\mathrm{P}(4-\mathrm{VPH}) \mathrm{ClO}_{4}$ at room temperature under solvent-free conditions.

\begin{tabular}{|c|c|c|c|c|c|}
\hline \multirow[b]{2}{*}{ Entry } & \multirow[b]{2}{*}{ Substrate } & \multicolumn{2}{|c|}{ Protection } & \multicolumn{2}{|c|}{ Deprotection } \\
\hline & & $\begin{array}{l}\text { Time } \\
\text { (min) }\end{array}$ & $\begin{array}{c}\text { Yield a,b } \\
(\%)\end{array}$ & $\begin{array}{l}\text { Time } \\
\text { (min) }\end{array}$ & $\begin{array}{c}\text { Yield a,b } \\
(\%)\end{array}$ \\
\hline 1 & $\mathrm{C}_{6} \mathrm{H}_{5} \mathrm{CHO}$ & 1 & 98 & 8 & 95 \\
\hline 2 & $2-\mathrm{NO}_{2}-\mathrm{C}_{6} \mathrm{H}_{4} \mathrm{CHO}$ & 1 & 91 & 8 & 70 \\
\hline 3 & $4-\mathrm{NO}_{2}-\mathrm{C}_{6} \mathrm{H}_{4} \mathrm{CHO}$ & 1 & 97 & 8 & 68 \\
\hline 4 & $2-\mathrm{Cl}-\mathrm{C}_{6} \mathrm{H}_{4} \mathrm{CHO}$ & 1 & 97 & 10 & 90 \\
\hline \multirow[t]{2}{*}{5} & $4-\mathrm{Cl}-\mathrm{C}_{6} \mathrm{H}_{4} \mathrm{CHO}$ & 1 & 97 & 15 & 96 \\
\hline & \multicolumn{5}{|c|}{$(1,1,1,1)^{c}(97,96,96,95)^{d}$} \\
\hline 6 & $4-\mathrm{CN}-\mathrm{C}_{6} \mathrm{H}_{4} \mathrm{CHO}$ & 1 & 92 & 12 & 72 \\
\hline 7 & $2-\mathrm{Me}-\mathrm{C}_{6} \mathrm{H}_{4} \mathrm{CHO}$ & 1 & 92 & 15 & 89 \\
\hline 8 & $4-\mathrm{Me}-\mathrm{C}_{6} \mathrm{H}_{4} \mathrm{CHO}$ & 1 & 94 & 12 & 86 \\
\hline 9 & 2-MeO- $\mathrm{C}_{6} \mathrm{H}_{4} \mathrm{CHO}$ & 1 & 91 & 25 & 78 \\
\hline 10 & 4-MeO- $\mathrm{C}_{6} \mathrm{H}_{4} \mathrm{CHO}$ & 1 & 93 & 25 & 75 \\
\hline 11 & $3,4-(\mathrm{MeO})_{2}-\mathrm{C}_{6} \mathrm{H}_{3} \mathrm{CHO}$ & 1 & 93 & 30 & 70 \\
\hline 12 & $2-\mathrm{OH}-\mathrm{C}_{6} \mathrm{H}_{4} \mathrm{CHO}$ & 1 & $92 \mathrm{e}$ & 5 & 95 \\
\hline 13 & $4-\mathrm{OH}-\mathrm{C}_{6} \mathrm{H}_{4} \mathrm{CHO}$ & 1 & $94 \mathrm{e}$ & 5 & 96 \\
\hline 14 & Furfural & 1 & 90 & 15 & 85 \\
\hline 15 & $\mathrm{C}_{6} \mathrm{H}_{5} \mathrm{CH}_{2} \mathrm{CHO}$ & 1 & 88 & 25 & 82 \\
\hline 16 & $\mathrm{Me}\left(\mathrm{CH}_{2}\right)_{4} \mathrm{CHO}$ & 1 & 86 & 30 & 70 \\
\hline 17 & $\mathrm{C}_{6} \mathrm{H}_{5} \mathrm{CH}=\mathrm{CHCHO}$ & 1 & 95 & 5 & 94 \\
\hline 18 & $1,2-\mathrm{C}_{6} \mathrm{H}_{4}(\mathrm{CHO})_{2}$ & 5 & $92^{\mathrm{f}}$ & 5 & 90 \\
\hline 19 & $1,3-\mathrm{C}_{6} \mathrm{H}_{4}(\mathrm{CHO})_{2}$ & 5 & $92^{f}$ & 5 & 95 \\
\hline 20 & $1,4-\mathrm{C}_{6} \mathrm{H}_{4}(\mathrm{CHO})_{2}$ & 5 & $96^{f}$ & 5 & 90 \\
\hline 21 & 2-Naphthaldehyde & 1 & 89 & 10 & 94 \\
\hline 22 & $\mathrm{C}_{6} \mathrm{H}_{5} \mathrm{COCH}_{3}$ & 120 & $0 \mathrm{~g}$ & 一 & 一 \\
\hline
\end{tabular}

a The products were characterized based on their physical properties and IR and NMR analyses.

b Isolated yield.

c The reaction time for recycled catalyst.

$\mathrm{d}$ The product for recycled catalyst.

e 3 equiv of $\mathrm{Ac}_{2} \mathrm{O}$ was used and product isolated as triacetate.

f 4 equiv of $\mathrm{Ac}_{2} \mathrm{O}$ was used and product isolated as tetraacetate.

g No product was detected.

ylated under the optimized conditions. Hydroxybenzaldehydes (Table 3, entries 12 and 13) and phthaldialdehyes (Table 3, entries 18-20) containing two types of acylatable group were completely acetylated to give the corresponding triacetate and tetraacetates. The application of the optimized conditions to acetophenone did not give any of the 1,1-diacetate product (Table 3, entry 22). For ortho-substituted aldehydes, where the ortho substituent was an acylatable group (Table 3, entries 12 and 18), $\mathrm{P}(4-\mathrm{VP}) \mathrm{ClO}_{4}$ was also equally efficient in catalyzing the acetylation.

The differences observed in the reactivity of aldehydes and ketones towards the formation of the corresponding 1,1-diacetate compounds encouraged us to evaluate the efficiency of $\mathrm{P}(4-\mathrm{VPH}) \mathrm{HClO}_{4}$ for the selective formation of a 1,1-diacetate species during inter- and intra-molecular competition between an aldehyde and a ketone. Thus, a mixture of benzaldehyde (1 $\mathrm{mmol})$ and acetophenone ( $1 \mathrm{mmol})$ was treated with $\mathrm{Ac}_{2} \mathrm{O}(1.5$ $\mathrm{mmol})$ in the presence of $\mathrm{P}(4-\mathrm{VPH}) \mathrm{ClO}_{4}(20 \mathrm{mg})$ at room temperature under solvent-free conditions for 2 min (Scheme 2). Benzaldehyde 1,1-diacetate was obtained in quantitative yield, whereas none of the 1,1-diacetate of acetophenone was observed (GC-MS). The treatment of 4-acetylbenzaldehyde (1 mmol) with $\mathrm{Ac}_{2} \mathrm{O}$ (1.5 mmol) for 2 min under similar conditions resulted in the exclusive formation of the 1,1-diacetate of the aldehyde group (Scheme 2).

The outstanding feature of this method was that the catalyst could be readily recycled five times without any significant reduction in its activity (Table 3, entry 5). There are several disadvantages associated with the use of solid acid catalysts such as leaching, which can lead to a reduction in the activity of the catalyst. The leaching of $\mathrm{P}(4-\mathrm{VPH}) \mathrm{ClO}_{4}$ into the liquid phase was rigorously checked using standard potentiometric and conductometric techniques after every run and the FTIR spectrum of the fresh catalyst was compared with that of the recovered catalyst after the 5th run [56]. The results of these analyses showed that no leaching had occurred during the reaction.

A comparison of this method with several other reported methods for the same transformation is shown in Table 4 and clearly shows the advantages of this method over the existing procedures. It is also clear that some of the previously reported procedures required much longer reaction time, did not allow for the recovery and reuse of the catalyst, or used a large excess of the acetylating agent. Our newly developed procedure was particularly efficient for the acetylation of 4-nitrobenzaldehyde, with the reaction affording $97 \%$ yield in $1 \mathrm{~min}$. In contrast, the same transformation required 20 equivalents of silica sulfuric acid so achieve similar yield in the same time period [61]. The use of $\mathrm{LiClO}_{4}$ was found to be equally as effective as our newly developed catalyst for the acetylation of 4-hydroxybenzaldehyde, although an extended reaction time was required in this case $(10 \mathrm{~h})$. Compared with K-10 [62], which had no effect on the acetylation of 4-hydroxybenzaldehyde, our newly developed catalytic system gave the desired product of $94 \%$ yield in only $1 \mathrm{~min}$.

It is noteworthy that perchlorates are potentially explosive when heated in the presence of combustible substances at high temperature $[68,69]$ and care should therefore be taken when handling perchlorates under these conditions. The conditions used in the current study only required the use of catalytic quantity of $\mathrm{P}(4-\mathrm{VPH}) \mathrm{ClO}_{4}$ under mild reaction conditions (room temperature), and therefore circumvented the potential hazards associated with the use of perchlorates. Furthermore, the fact that $\mathrm{P}(4-\mathrm{VPH}) \mathrm{ClO}_{4}$ can be easily handled as a non-corrosive powder and readily separated from the reaction mixture by filtration and reused without any significant loss in activity

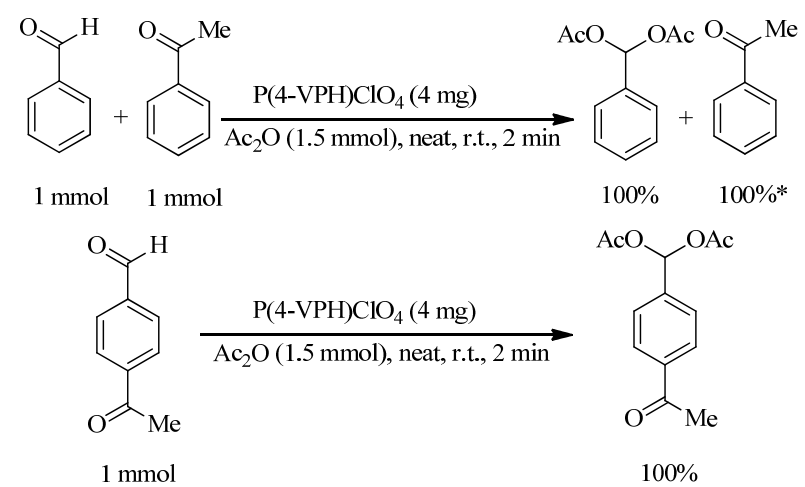

Scheme 2. Selectivity in acylal formation during inter- and intra-molecular competition reactions. *Acetophenon 1,1-diacetate was not obtained and only initial reactant was observed. 
Table 4

Comparison of the effects of different catalysts on the synthesis of the 1,1-diacetates from different aldehydes.

\begin{tabular}{|c|c|c|c|c|c|c|}
\hline Entry & Substrate & Catalyst & $\mathrm{Ac}_{2} \mathrm{O}$ (equiv.) & Time (min) & Yield a $(\%)$ & Ref. \\
\hline \multirow[t]{7}{*}{1} & 4-Nitrobenaldehyde & $\mathrm{P}(4-\mathrm{VP}) \mathrm{HSO}_{4}$ & $1.1-3.3$ & 4 & 98 & [29] \\
\hline & & Silica sulfuric acid & 20 & $50 \mathrm{~s}$ & 99 & [61] \\
\hline & & Silica supported perchloric acid & 2 & 5 & 96 & [63] \\
\hline & & $\mathrm{Cu}\left(\mathrm{ClO}_{4}\right)_{2} \cdot 6 \mathrm{H}_{2} \mathrm{O}$ & 2 & 10 & 97 & [64] \\
\hline & & $\mathrm{Zn}\left(\mathrm{ClO}_{4}\right)_{2} \cdot 6 \mathrm{H}_{2} \mathrm{O}$ & 1.5 & 2 & 92 & [65] \\
\hline & & $\mathrm{KHSO}_{4}$ & 2 & 90 & 96 & {$[66]$} \\
\hline & & $\mathrm{P}(4-\mathrm{VP}) \mathrm{ClO}_{4}$ & 1.5 & 1 & 97 & this work \\
\hline \multirow[t]{6}{*}{2} & 4-Hydroxybenzaldehyde & $\mathrm{P}(4-\mathrm{VP}) \mathrm{HSO}_{4}$ & $1.1-3.3$ & 24 & 88 & [29] \\
\hline & & Silica sulfuric acid & 15 & $70 \mathrm{~s}$ & 99 & [61] \\
\hline & & Silica supported perchloric acid & 2 & 5 & 82 & [63] \\
\hline & & $\mathrm{Cu}\left(\mathrm{ClO}_{4}\right)_{2} \cdot 6 \mathrm{H}_{2} \mathrm{O}$ & 2.5 & 30 & 92 & [64] \\
\hline & & $\mathrm{LiClO}_{4}$ & 1.7 & 600 & 95 & [67] \\
\hline & & $\mathrm{P}(4-\mathrm{VP}) \mathrm{ClO}_{4}$ & 1.5 & 1 & 94 & this work \\
\hline \multirow[t]{4}{*}{3} & 4-Cyanobenzaldehyde & $\mathrm{P}(4-\mathrm{VP}) \mathrm{HSO}_{4}$ & $1.1-3.3$ & 55 & 72 & [29] \\
\hline & & Solid silica sulfuric acid & 15 & $50 \mathrm{~s}$ & 98 & [61] \\
\hline & & $\mathrm{Zn}\left(\mathrm{ClO}_{4}\right)_{2} \cdot 6 \mathrm{H}_{2} \mathrm{O}$ & 1.5 & 5 & 98 & [65] \\
\hline & & $\mathrm{P}(4-\mathrm{VP}) \mathrm{ClO}_{4}$ & 1.5 & 1 & 92 & this work \\
\hline \multirow[t]{8}{*}{4} & 4-Chlorobenzaldehyde & $\mathrm{P}(4-\mathrm{VP}) \mathrm{HSO}_{4}$ & $1.1-3.3$ & 10 & 88 & [29] \\
\hline & & Silica sulfuric acid & 3 & 1 & 82 & [61] \\
\hline & & Silica supported perchloric acid & 2 & 2 & 98 & [63] \\
\hline & & $\mathrm{Cu}\left(\mathrm{ClO}_{4}\right)_{2} \cdot 6 \mathrm{H}_{2} \mathrm{O}$ & 2 & 2 & 97 & [64] \\
\hline & & $\mathrm{Zn}\left(\mathrm{ClO}_{4}\right)_{2} \cdot 6 \mathrm{H}_{2} \mathrm{O}$ & 1.5 & 3 & 91 & [65] \\
\hline & & $\mathrm{KHSO}_{4}$ & 2 & 3 & 99 & [66] \\
\hline & & $\mathrm{LiClO}_{4}$ & 1.7 & 30 & 90 & [67] \\
\hline & & $\mathrm{P}(4-\mathrm{VP}) \mathrm{ClO}_{4}$ & 1.5 & 1 & 97 & this work \\
\hline
\end{tabular}

a Isolated yield.

makes it especially suitable for industrial application.

Although a detailed mechanism for the current transformation has not yet been established, similar mechanisms have been proposed for acetylation reactions conducted in the presence of perchlorate as a promoter [64]. On the basis of literature studies, a plausible catalytic cycle for the regeneration of $\mathrm{P}(4-\mathrm{VPH}) \mathrm{ClO}_{4}$ has been proposed, as shown in Scheme 3. Thus, the acylation involves the initial formation of $\mathrm{AcClO}_{4}$ together with $\mathrm{P}(4-\mathrm{VPH}) \mathrm{OAc}$, which subsequently reacts with the aldehyde to give the acylal with the concomitant regeneration of $\mathrm{P}(4-\mathrm{VPH}) \mathrm{ClO}_{4}$. Further investigations aimed at fully elucidating the precise mechanism of this reaction are currently underway in our laboratory.

\section{Conclusions}

We have successfully developed for the first time a method for the acetylation of aldehydes at room temperature under solvent-free conditions using the solid phase catalyst

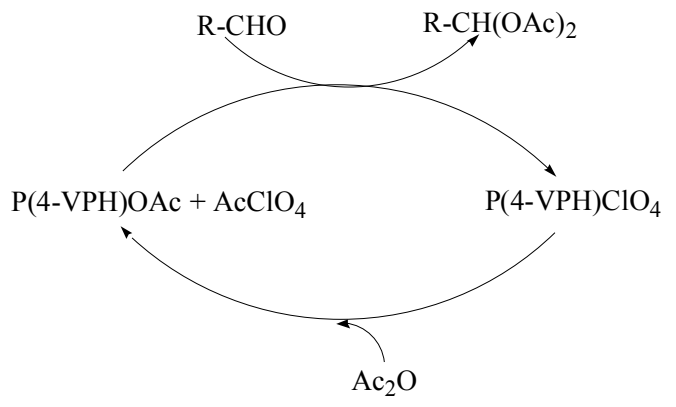

Scheme 3. Proposed mechanism for the 1,1-diacetylation of aldehydes.
$\mathrm{P}(4-\mathrm{VPH}) \mathrm{ClO}_{4}$ as a catalyst. The methodology has several advantages from a green chemistry perspective, including avoiding toxic catalysts and solvents. Furthermore, the reaction proceeds at a fast rate to afford the desired products in excellent yields with no by-products observed. The catalyst was also inexpensive, easy to prepare and handle, and could be readily recovered and reused without any significant loss in its activity. Further work is currently underway in our laboratory to explore the potential uses of this new catalyst in other organic transformations.

\section{Acknowledgments}

The author is thankful to House Research of Professor Reza, Education Guilan for partial support of this work.

\section{References}

[1] Stinson S C. Chem Eng News, 1996, 74: 75

[2] Tanaka K, Toda F. Chem Rev, 2000, 100: 1025

[3] Melero J A, van Grieken R, Morales G. Chem Rev, 2006, 106: 3790

[4] Rao V, Ashokan P V, Shridhar M H. Mater Sci Eng A, 2000, 276: 266

[5] Choudhary D, Paul S, Gupta R, Clark J H. Green Chem, 2006, 8: 479

[6] Ghorbani-Choghamarani A, Sardari S. J Sulfur Chem, 2011, 32: 63

[7] Dalpozzo R, Bartoli G, Sambri L, Melchiorre P. Chem Rev, 2010, 110: 3501

[8] Chakraborti A K, Singh B, Chankeshwara S V, Patel A R.J Org Chem, 2009, 74: 5967

[9] Sharma G, Kumar R, Chakraborti AK.J Mol Catal A, 2007, 263: 143

[10] Chankeshwara S V, Chakraborti A K. J Mol Catal A, 2006, 253: 198

[11] Chakraborti A K, Kondaskar A, Rudrawar S. Tetrahedron, 2004, 60: 9085 


\section{Graphical Abstract}

Chin. J. Catal., 2014, 35: 329-334 doi: 10.1016/S1872-2067(12)60750-5

Poly(4-vinylpyridinium) perchlorate as an efficient solid acid catalyst for the chemoselective preparation of 1,1-diacetates from aldehydes under solvent-free conditions

Nader Ghaffari Khaligh*

House Research of Professor Reza, Iran

Poly(4-vinylpyridinium) perchlorate was used as a catalyst for the acetylation of aliphatic and aromatic aldehydes under solvent-free conditions. Ketones were unaffected by the reaction conditions and the catalyst could be reused several times without any loss in activity.

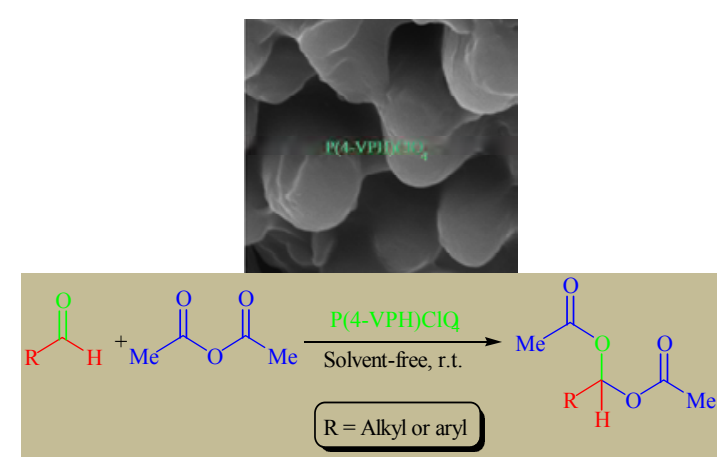

[12] Chakraborti A K, Rudrawar S, Kondaskar A. Org Biomol Chem, 2004, 2: 1277

[13] Sharma G, Kumar R, Chakraborti A K. Tetrahedron Lett, 2008, 49: 4272

[14] Karimi B, Khalkhali M. J Mol Catal A, 2005, 232: 113

[15] Niknam K, Saberi D, Sefat M N. Tetrahedron Lett, 2009, 50: 4058

[16] Tanabe K, Hölderich W F. Appl Catal A, 1999, 181: 399

[17] Cotelle P, Catteau J P. Tetrahedron Lett, 1992, 33: 3855

[18] Jin T S, Ma Y R, Zhang Z H, Li T S. Org Prep Proced Int, 1998, 30: 463

[19] Kochhar K S, Bal B S, Deshpande R P, Rajadhyaksha S N, Pinnick H W. J Org Chem, 1983, 48: 1765

[20] Jin T S, Du G Y, Li T S. Indian J Chem Sect B, 1998, 37: 939

[21] Perez E R, Marrero A L, Perez R, Autie M A. Tetrahedron Lett, 1995 , 36: 1779

[22] Davey W, Gwilt J R.J Chem Soc, 1957: 1008

[23] Tomita M, Kikuchi T, Bessho K, Hori T, Inubushi Y. Chem Pharm Bull, 1963, 11: 1484

[24] Gregory M J.J Chem Soc B, 1970: 1201

[25] Marshall J A, Wuts P G M. J Org Chem, 1977, 42: 1794

[26] Freeman F, Karchefski E M. J Chem Eng Data, 1977, 22: 355

[27] Kavala V, Patel B K. Eur J Org Chem, 2005, 2: 441

[28] Shirini F, Mamaghani M, Mostashari-Rad T, Abedini M. Bull Korean Chem Soc, 2010, 31: 2399

[29] Khaligh N G, Shirini F. J Mol Catal A, 2011, 348: 20

[30] Shirini F, Jolodar O G. J Mol Catal A, 2012, 356: 61

[31] Aggarwal V K, Fonquerna S, Vennall G P. Synlett, 1998: 849

[32] Chandra K L, Saravanan P, Singh V K. Synlett, 2000: 359

[33] Karimi B, Maleki J.J Org Chem, 2003, 68: 4951

[34] Carrigan M D, Eash K J, Oswald M C, Mohan R S. Tetrahedron Lett, 2001, 42: 8133

[35] Roy S C, Banerjee B. Synlett, 2002: 1677

[36] Yadav J S, Reddy B V S, Srinivas Ch. Synth Commun, 2002, 32: 2169

[37] Jin T S, Sun G, Li Y W, Li T S. Green Chem, 2002, 4: 255

[38] Michie J K, Miller J A. Synthesis, 1981: 824

[39] Deka N, Kalita D J, Borah R, Sarma J C. J Org Chem, 1997, 62: 1563

[40] Deka N, Borah R, Kalita D J, Sarma J C. J Chem Res, 1998: 94

[41] Aggen D H, Arnold J N, Hayes P D, Smoter N J, Mohan R S. Tetrahedron, 2004, 60: 3675
[42] Sumida N, Nishioka K, Sato T. Synlett, 2001: 1921

[43] Yadav J S, Reddy B V S, Venugopal C, Ramalingam T. Synlett, 2002: 604

[44] Saburi E, Davoodnia A, Tavakoli-Hoseini N. Synth React Inorg Met-Org Nano-Met Chem, 2011, 41: 1063

[45] Olah G A, Mehrotra A K. Synthesis, 1982: 962

[46] Kumar P, Hegde V R, Kumar T P. Tetrahedron Lett, 1995, 36: 601

[47] Raju S V N. J Chem Res, 1996: 68

[48] Curini M, Epifano F, Marcotullio M C, Rosati O, Nocchetti M. Tetrahedron Lett, 2002, 43: 2709

[49] Tamaddon F, Amrollahi M A, Sharafat L. Tetrahedron Lett, 2005, 46: 7841

[50] Sarvari M H, Sharghi H. Tetrahedron, 2005, 61: 10903

[51] Firouzabadi H, Iranpoor N, Nowrouzi F, Amani K. Tetrahedron Lett, 2003, 44: 3951

[52] Khan A T, Choudhury L H, Ghosh S. Eur J Org Chem, 2005: 2782

[53] Khan A T, Islam S, Majee A, Chattopadhyay T, Ghosh S. J Mol Catal A, 2005, 239: 158

[54] Shirini F, Akbari-Dadamahaleh S, Mohammad-Khah A.J Mol Catal A, 2012, 363-364: 10

[55] Karimi B, Seradj H, Ebrahimian G R. Synlett, 2000: 623

[56] Khaligh N G. J Mol Catal A, 2012, 363-364: 90

[57] Khaligh N G, Shirini F. Ultrason Sonochem, 2013, 20: 26

[58] Reddy B M, Thirupathi B, Patil M K. Open Catal J, 2009, 2: 33

[59] Khaligh N G. Catal Sci Technol, 2012, 2, 2211

[60] Appaturi J N, Adam F. Appl Catal B, 2013, 136-137: 150

[61] Wu H, Shen Y, Fan LY, Wan Y, Shi D Q. Tetrahedron, 2006, 62: 7995

[62] Zhang Z H, Li T S, Fu C G.J Chem Res, 1997: 174

[63] Khan A T, Choudhury L H, Ghosh S. J Mol Catal A, 2006, 255: 230

[64] Jeyakumar K, Chand D K. J Mol Catal A, 2006, 255: 275

[65] Kumar R, Thilagavathi R, Gulhane R, Chakraborti A K. J Mol Catal A, 2006, 250: 226

[66] Heravi M M, Bakhtiari K, Taheri S, Oskooie H A. Green Chem, 2005, 7: 867

[67] Ziyaei A, Azizi N, Saidi M R.J Mol Catal A, 2005, 238: 138

[68] Schumacher J C. Perchlorates: Their Properties, Manufacture and Uses. New York: Reinhold, 1960

[69] Long J R. Chem Health Saf, 2002, 9: 12 